\title{
Design of a Selective Filter-Antenna with Low Insertion Loss and High Suppression Stopband for WiMAX Applications
}

\author{
Alkhafaji MK*, Sahbudin RKZ, Ismail AB and Hashim SJ
}

Department of Computer and Communication System Engineering, Center of Excellence of Wireless and Photonics Network (WIPNET), UPM, 43400-Serdang, Malaysia

\begin{abstract}
This paper presents a selective quasi-elliptic bandpass filter-antenna. The presented filter-antenna has a low insertion loss in the passband and relatively high stopband rejection. This structure consists of a quasi-elliptic bandpass filter direct coupled with patch antenna. The bandpass filter consists of four $(\lambda / 4)$ spiral square resonators. It has operates between (3.25-3.6) GHz so it is suitable for WiMAX applications. A CST Microwave Studio Suite software has used to simulate the filter-antenna circuit. The simulated results of the patch antenna and the results of the filter-antenna appears a good matching between the two circuits.
\end{abstract}

Keywords: Quasi-elliptic; Bandpass filter; Filter-antenna; Insertion loss; Spiral square resonators; CST Microwave studio suite; Patch antenna

\section{Introduction}

The large and rapid progress of wireless communication, systems emerged as the urgent need to reduce the size, weight, and cost of the receiving and transmitting circuits. It has become one of the important requirements in the recent years. To obtain these aims, several attempts could be design at the same time in a single circuit module. In order to reduce the overall circuit size, a predesigned bandpass filter with appropriate configuration is inserting directly into the feed location of a patch antenna. The bandpass filter can be integrate completely with the antenna for a required bandwidth [1]. A bandpass filter is composed of resonators having the identical resonant frequency as the antenna. This case leads to interference between the return loss and the antenna gain responses, especially at the band edges. It is usually that the impedance bandwidth of the antenna is different from that of the bandpass filter [2]. Typically, input/output ports design of a bandpass filter is usually takes as $50 \Omega$ terminations. Although, the antenna input impedance may be not perfectly match to a $50 \Omega$ at the band edges. The regression due to mismatch thus takes place. Both components have in general arranged at the highly front-end of communication system. Integration of the antenna and the bandpass filter has been considered for boosting the total performance and decreasing the circuit size [3]. In the recent years, many academic scholars began to study the co-design process for the bandpass filters and the antennas. By optimizing the impedance at the interfaces of the filter and the antenna, the impedance bandwidth has enhanced [4]. The filter-antennas, which designed by using the bandpass filter synthesis method, the shaped antenna and the rectangle patch antenna has replaced with the last resonator, and the load impedance of a bandpass filter [5]. The dimensions of the shaped antenna and the rectangle patch antenna in order of half-wavelength. To get an easy mobility, for modern wireless communication systems, the transmitting and receiving components should have minimum dimensions. The integration of the bandpass filter to the antenna in a single module contributes to make the dimensions of the transmitters and receivers minimum [6]. Usually, in RF/Microwave front-end systems, a bandpass filter is cascaded to the antenna to reject the spurious signals that received or transmitted by the antenna [7]. Different research groups have examined the capability to use dielectric resonator (DR) antenna simultaneously for filtering, packaging, and oscillating purposes. However, there is no work has been done to integrate a filter and an antenna using a single resonator [8].
Bandpass filter provides a low insertion loss within the passband and a high attenuation in the stopband, and they can be realized by cascading lowpass filters and highpass filters, where the layouts are efficient and uncomplicated [9]. Edge coupled line filters become compact in size when their resonators folded, therefore the spurious pass zone becomes closer to the essential band and the selectivity of the filter becomes more flat [10]. The design process and purpose of the filter-antenna are differing from those of the traditional antenna. The filter-antenna circuit is not just another impedance matching technique, but also a forming for a filter and antenna gain and input return loss [11].

This paper presents an integration between a quasi-elliptic bandpass filter and the patch antenna to create a filter-antenna. This circuit has good specifications in terms of the matching between the two devices and a relatively low insertion loss in the pass band and has a high suppression on a spurious harmonics in the stop band. The filterantenna circuit presented here is suitable for WiMAX applications, because the circuit operates within the frequency range (3.25-3.6) $\mathrm{GHz}$. The selectivity of this circuit considered good in general.

This paper presents a filter-antenna design using $(\lambda / 4)$ spiral square resonator as the basic unit. Figure 1 depicts the layout of the basic unit resonator (Table 1).

\section{Quasi-Elliptic Bandpass Filter Design and Results}

This filter has in-between solution for Chebyshev and Ellipticfunction type filters. The transfer function for a quasi-elliptic filter is Amaya et al. [12]:

${ }^{*}$ Corresponding author: Alkhafaji MK, Faculty of Engineering, Department of Computer and Communication System Engineering, Center of Excellence of Wireless and Photonics Network (WIPNET), UPM, 43400-Serdang, Malaysia, Tel: +60 3-8946 6283; E-mail: mkks67@yahoo.com

Received July 27, 2016; Accepted September 17, 2016; Published September 23, 2016

Citation: Alkhafaji MK, Sahbudin RKZ, Ismail AB, Hashim SJ (2016) Design of a Selective Filter-Antenna with Low Insertion Loss and High Suppression Stopband for WiMAX Applications. Int J Sens Netw Data Commun 5: 147. doi: 10.4172/20904886.1000147

Copyright: (c) 2016 Alkhafaji MK, et al. This is an open-access article distributed under the terms of the Creative Commons Attribution License, which permits unrestricted use, distribution, and reproduction in any medium, provided the original author and source are credited. 


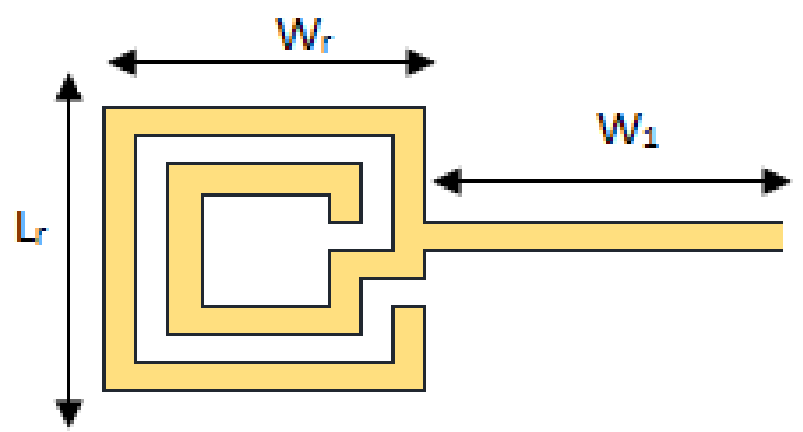

Figure 1: Graph between SNR vs. normalized CFO.

\begin{tabular}{|c|c|c|c|c|c|c|c|}
\hline $\mathbf{W r}$ & $\mathbf{W 1}$ & $\mathbf{W 2}$ & $\mathbf{W 3}$ & $\mathbf{W 4}$ & $\mathbf{W m}$ & $\mathbf{L r}$ & Ls \\
\hline 6 & 11.20 & 3.5 & 0.6 & 1.2 & 2.4 & 6 & 1 \\
\hline L1 & L2 & L3 & L4 & L5 & L6 & L7 & - \\
\hline 2.4 & 1.8 & 0.6 & 6.4 & 9.55 & 8.85 & 3.6 & - \\
\hline
\end{tabular}

Table 1: Quasi-elliptic bandpass filter dimensions $(\mathrm{mm})$.

$$
\left|s_{21}\right|=\frac{1}{1+\epsilon^{2} F_{N}^{2}(\Omega)}
$$

Where $\Omega$ is the frequency variable, which is normalized to the passband cutoff frequency of a lowpass prototype filter, and $\in$, is a ripple constant related to a given return loss LR described by:

$$
\in=\frac{1}{\sqrt{10^{-\left(L_{R} / 10\right)-1}}}
$$

In addition, $F_{N}(\Omega)$ for the selective filter has stated as a function of the pair of attenuation poles so that $\Omega=\Omega_{\mathrm{s}}\left(\Omega_{\mathrm{s}}>1\right)$ match to their frequency response locations. The locations of the pair of attenuation poles of the bandpass filter namely $\omega_{\mathrm{s} 1}$ and $\omega_{\mathrm{s} 2}$, are given by

$$
\begin{aligned}
& \omega_{s 1}=\omega_{0} \frac{-\Omega_{s} F B W+\sqrt{\left(\Omega_{s} F B W\right)^{2}+4}}{2} \\
& \omega_{s 2}=\omega_{0} \frac{\Omega_{s} F B W+\sqrt{\left(\Omega_{s} F B W\right)^{2}+4}}{2}
\end{aligned}
$$

Before integrating filter and antenna, a four-spiral resonator quasi-elliptic bandpass filter has designed. The bandpass filter operates at $\mathrm{f}_{\mathrm{c}}=3.33 \mathrm{GHz}$ with Fractional Bandwidth (FBW) of $10 \%$. The filter designed using the standard filter synthesis technique. In order to obtain the design parameters, RT/Duroid 5880 substrate had been used $\left(\varepsilon_{\mathrm{r}}=2.2\right)$, and $\mathrm{h}=0.786 \mathrm{~mm}$. Figure 2 shows the layout of the bandpass filter,

The response of the bandpass filter represented by $\mathrm{S} 11(\mathrm{~dB})$ and S21 (dB) parameters has illustrated in Figure 3. The curves for various values of the distance between two-neighbor resonators (Ls) show a good performance in passband and stopband. Figure 4 shows the bandpass filter Voltage/current matrix coefficient of the Z-impedance.

\section{Antenna Design and Results}

Figure 5 illustrates the geometry of the patch antenna design. As shown in the figure, the radiating component is a rectangular patch antenna with top T-shape band notch, and two bottom L-shape notches. These top and bottom notches have found to improve the patch antenna bandwidth as shown in Figure 6 which is illustrated the reflection coefficient parameter S11 (dB) of the patch antenna, and as it is seen that the patch antenna has a center frequency located at $3.42 \mathrm{GHz}$. The patch antenna fed by a $50 \Omega$ microstrip transmission line. CST Microwave Studio Suite has employed to perform the design and optimization process. The design parameters of the patch antenna have stated in Table 2. Figure 7 shows the Voltage Standing Wave ratio (VSWR) of the patch antenna.

\section{Filter-antenna Design and Results}

Figure 7 shows the geometry of the quasi-elliptic filter-antenna structure. The microstrip line feeding of the patch antenna has replaced by a quasi-elliptic filter and the performance of this arrangement have observed and compared with the performance of the patch antenna fed by the microstrip transmission line. Figure 8 shows the reflection coefficient S11 (dB) of the filter-antenna for various values of the distance Ls. Table 3 shows the dimensions of the filter-antenna bottom view $(\mathrm{mm})$.

Figure 9 shows the optimized performance of the filter-antenna, it illustrated the reflection coefficient $S 11(\mathrm{~dB})$ and gain $(\mathrm{dB})$. It can be

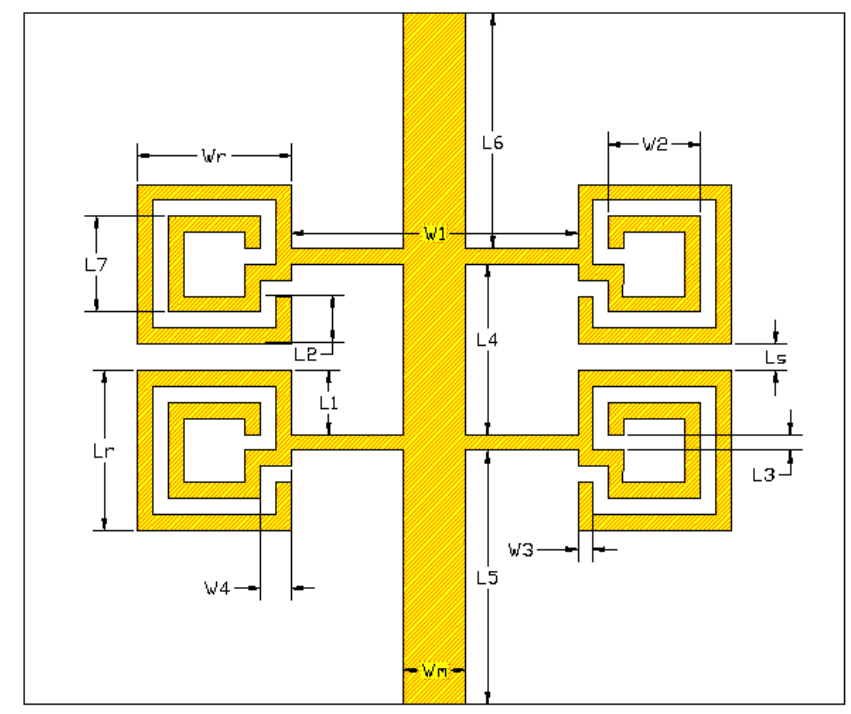

Figure 2: Direct couple four spiral resonators of the quasi-elliptic bandpass filter design.

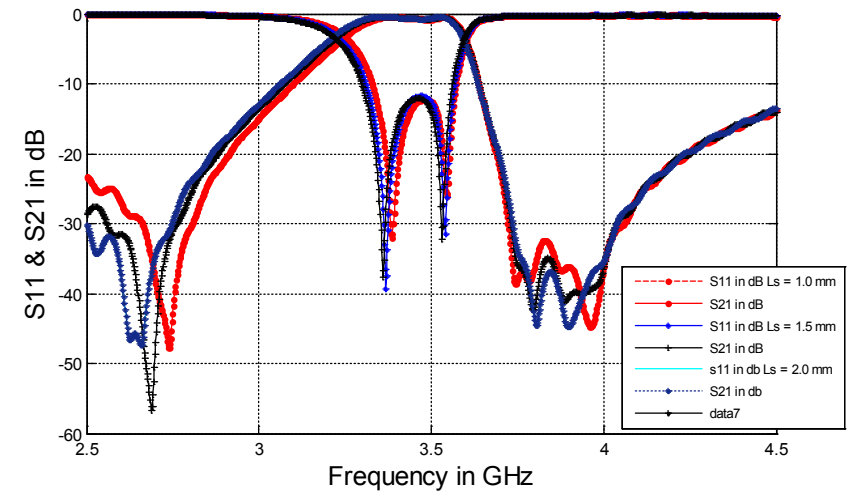

Figure 3: VSWR of the proposed quasi-elliptic bandpass filter. 


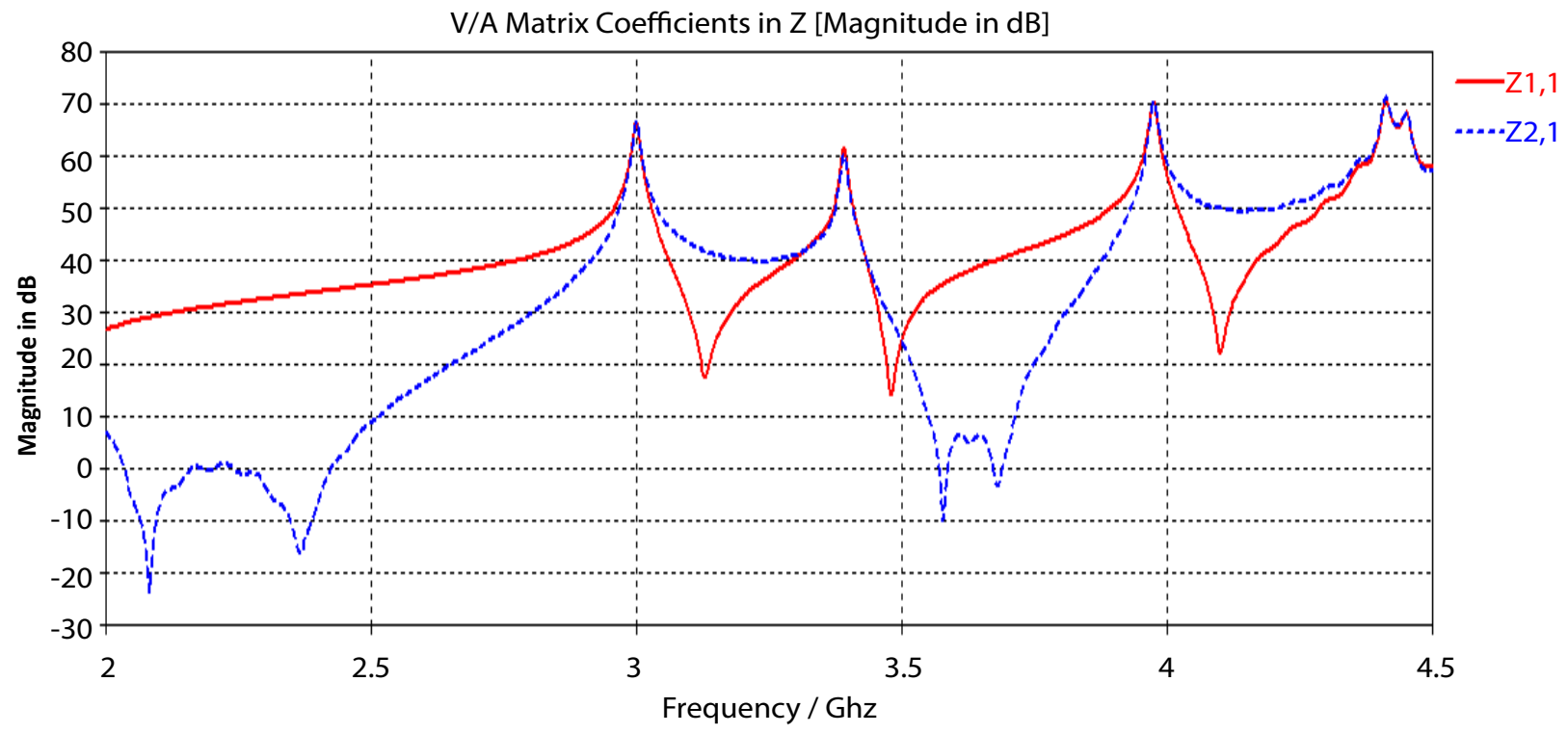

Figure 4: Voltage/Current matrix coefficients for the Z-impedance.

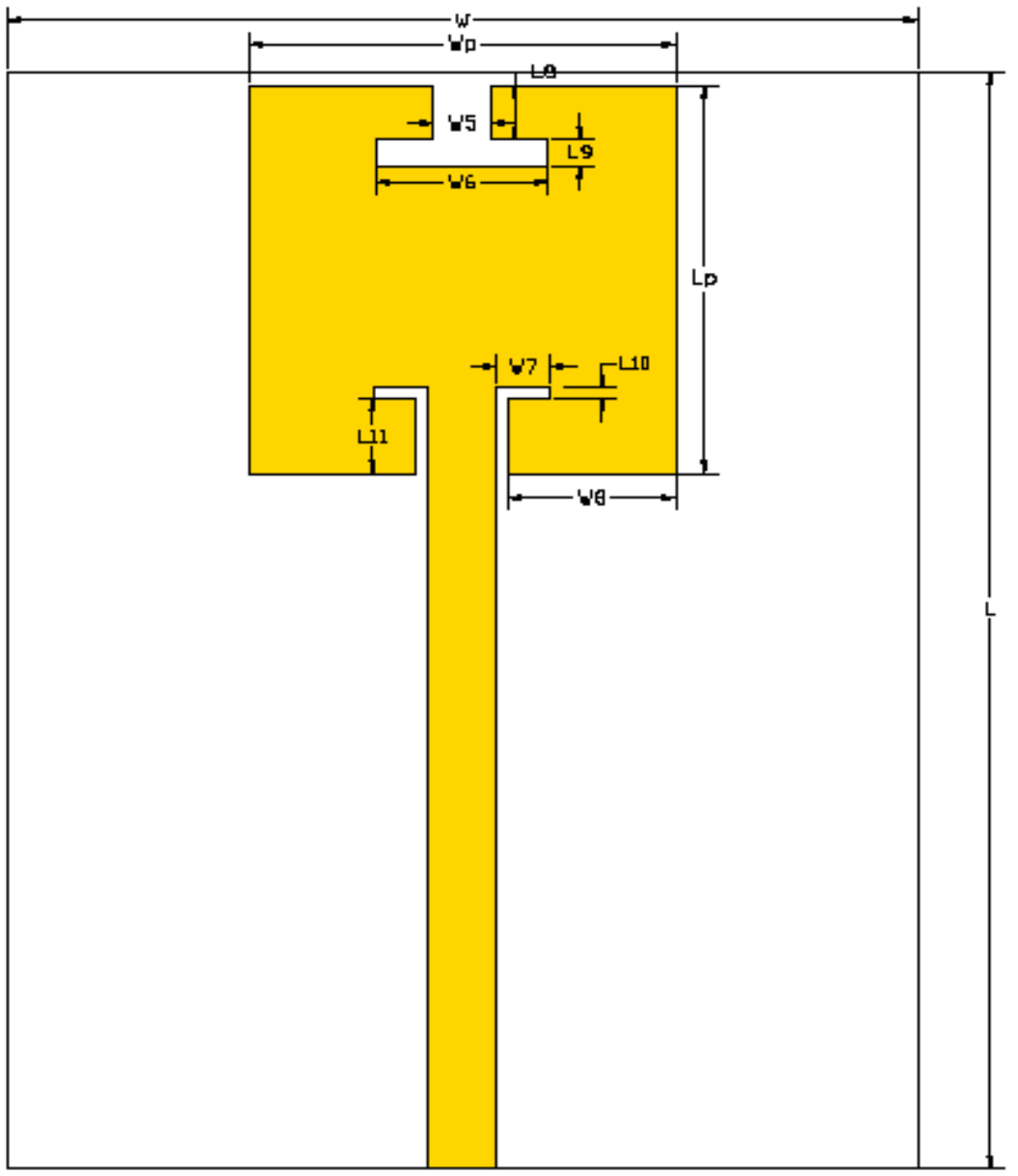

Figure 5: The geometry of the patch antenna 


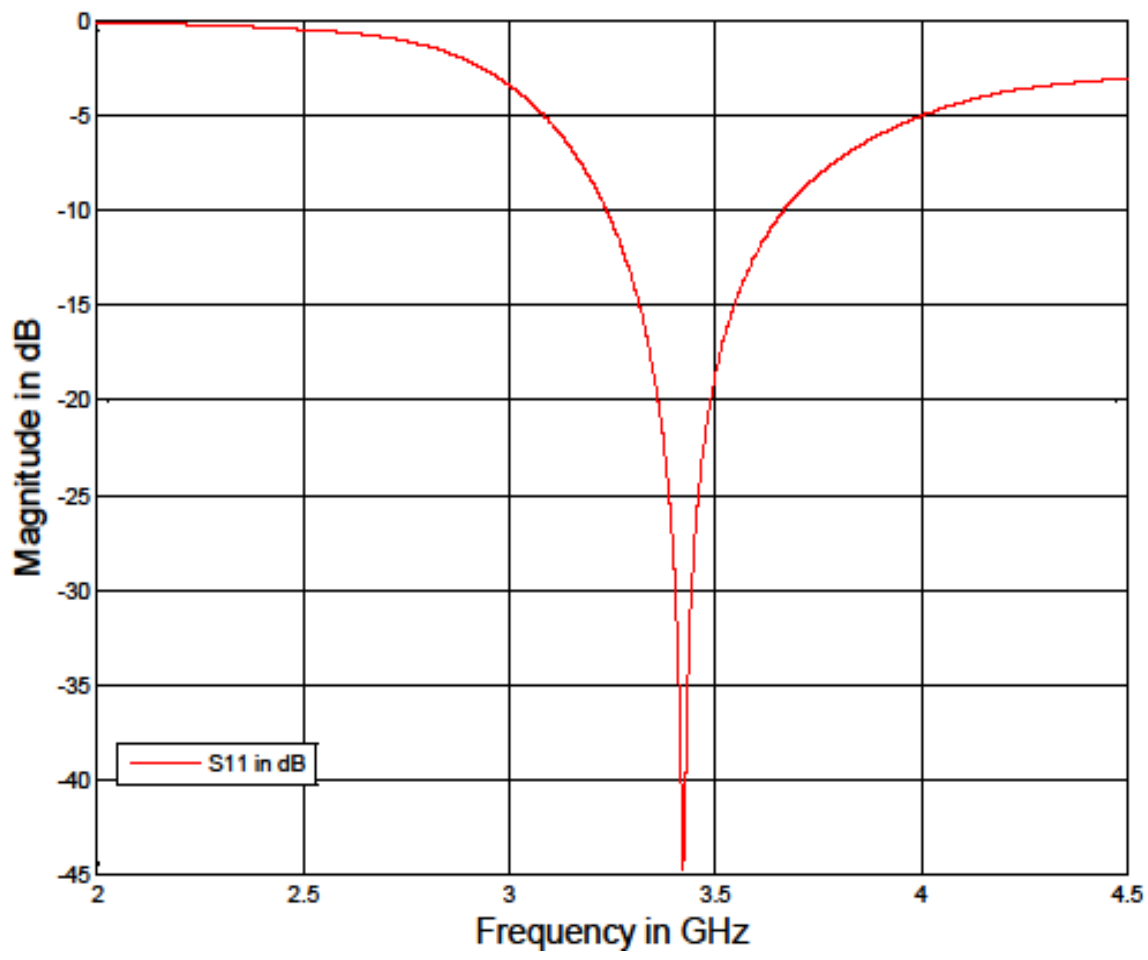

Figure 6: Return loss of the proposed patch antenna.

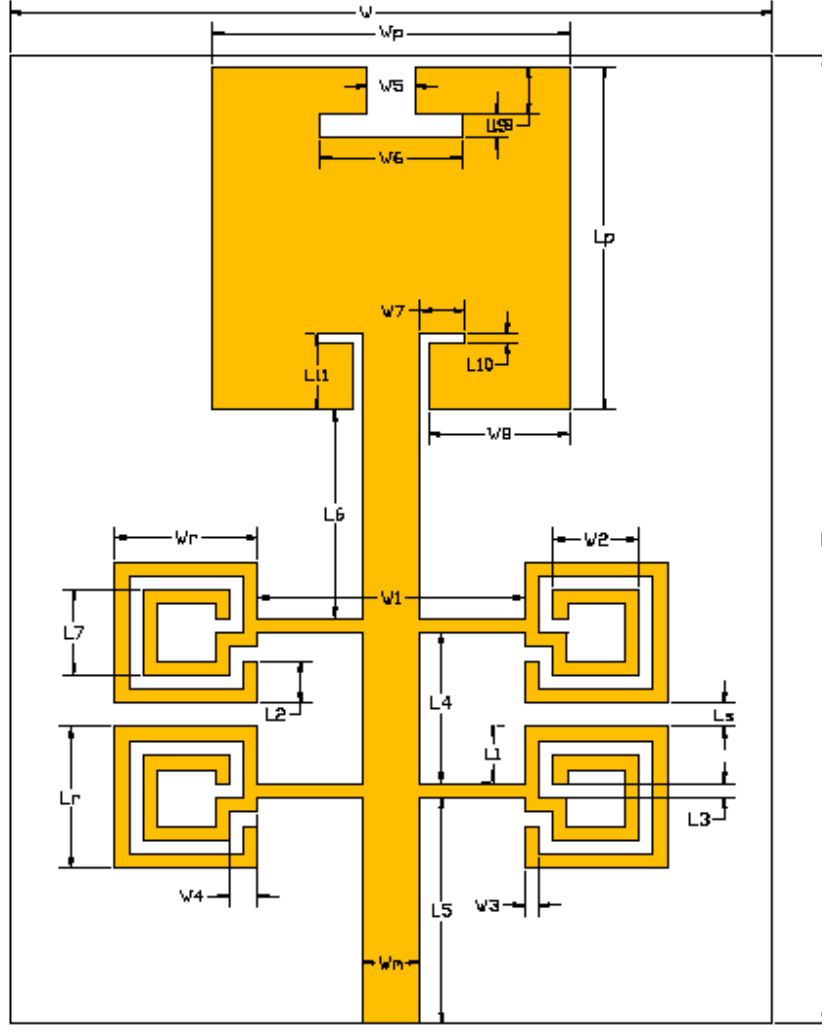

(a)

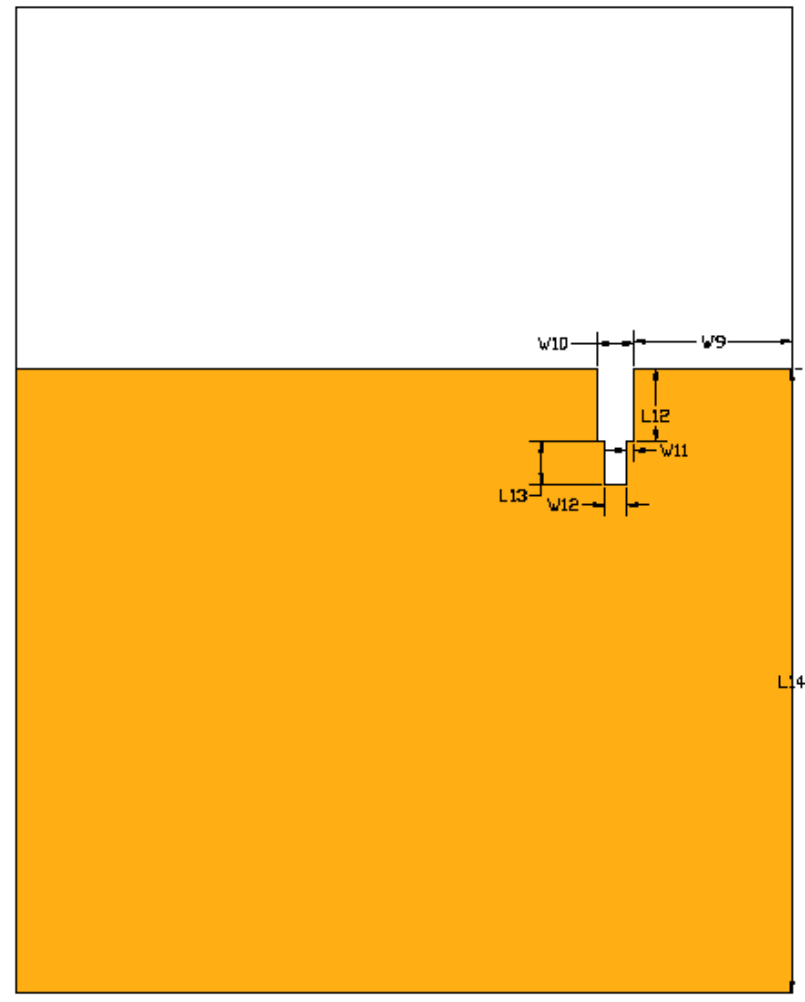

(b)

Figure 7: The geometry of the proposed filter-antenna (a) top view (b) bottom view. 
seen from that the filter-antenna has a bandwidth equal to $350 \mathrm{MHz}$ (from $3.25 \mathrm{MHz}-3.6 \mathrm{MHz}$ ), and a center frequency located at 3.425 $\mathrm{GHz}$ with the peak gain of about $4.9 \mathrm{dBi}$. This is clearly indicates the high matching between the filter and the antenna. In addition, a radiation null located at $3.75 \mathrm{GHz}$, and the frequency skirt selectivity becomes better.

Figure 10 shows the Voltage Standing Wave Ratio (VSWR) of the filter-antenna and that of the patch antenna.

Figure 11 shows the simulated farfield gain and directivity of the proposed filter-antenna at the center frequency.

\section{Conclusion}

A selective quasi-elliptic bandpass filter-antenna with low insertion loss and high suppression stop band has discussed in this paper. The design has accomplished by first establishing and analyzing the basic unit $(\lambda / 4)$ resonator and the complete fourresonator quasi-elliptic bandpass filter. The patch antenna with $\mathrm{T}-$ shape band notch from the top and two L-shape notches from the bottom had used as a radiating component. In this design the feeding microstrip transmission line of the patch antenna, has replaced by the quasi-elliptic bandpass filter to give filtering specifications. The

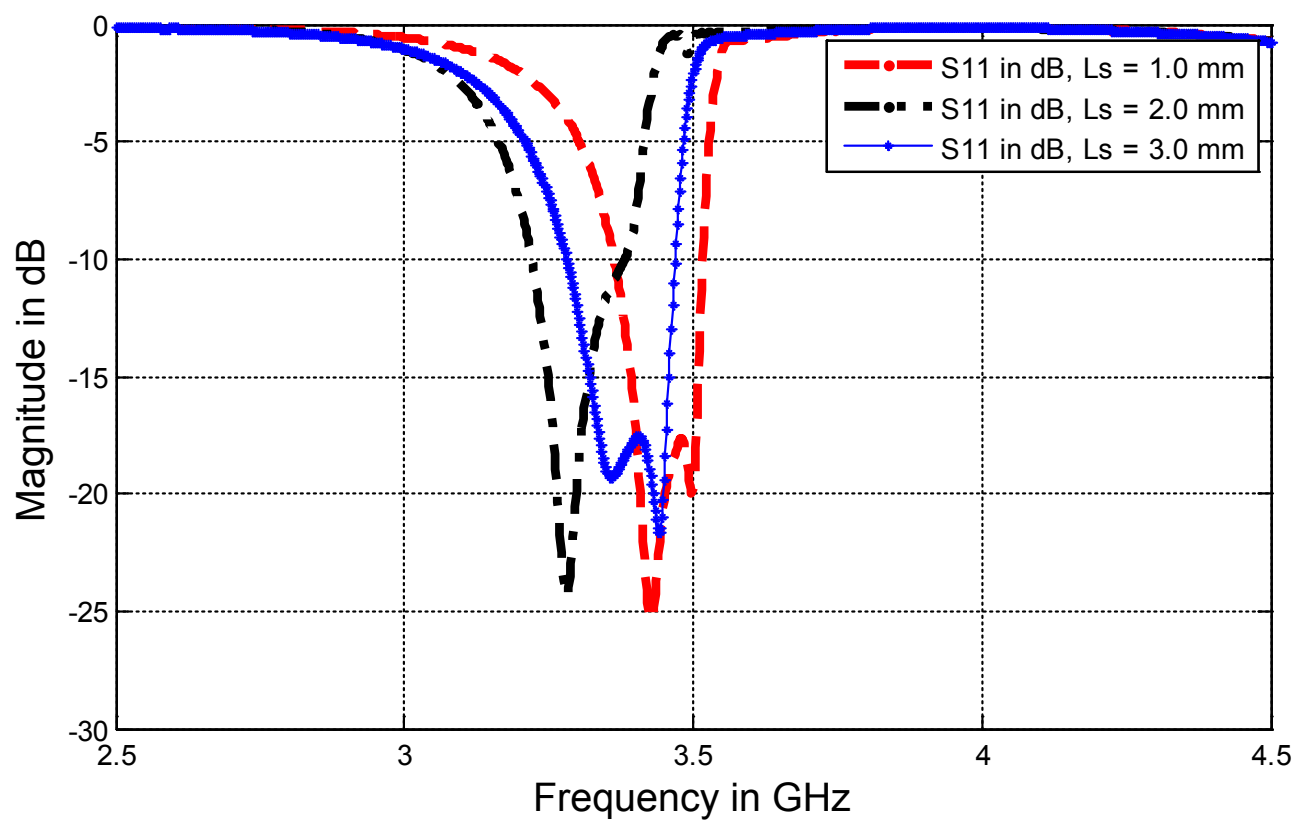

Figure 8: Return loss of the proposed filter-antenna for various values of Ls.

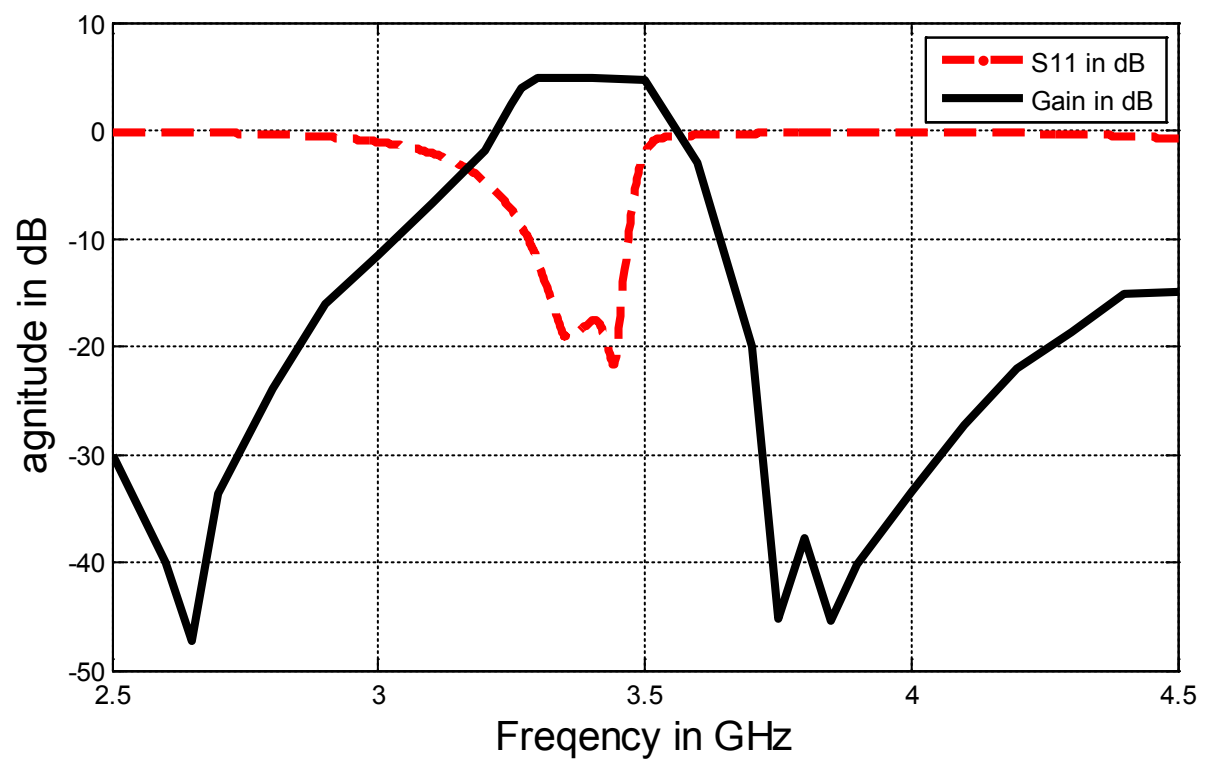

Figure 9: Filter-antenna performance (S11-parameter and gain). 


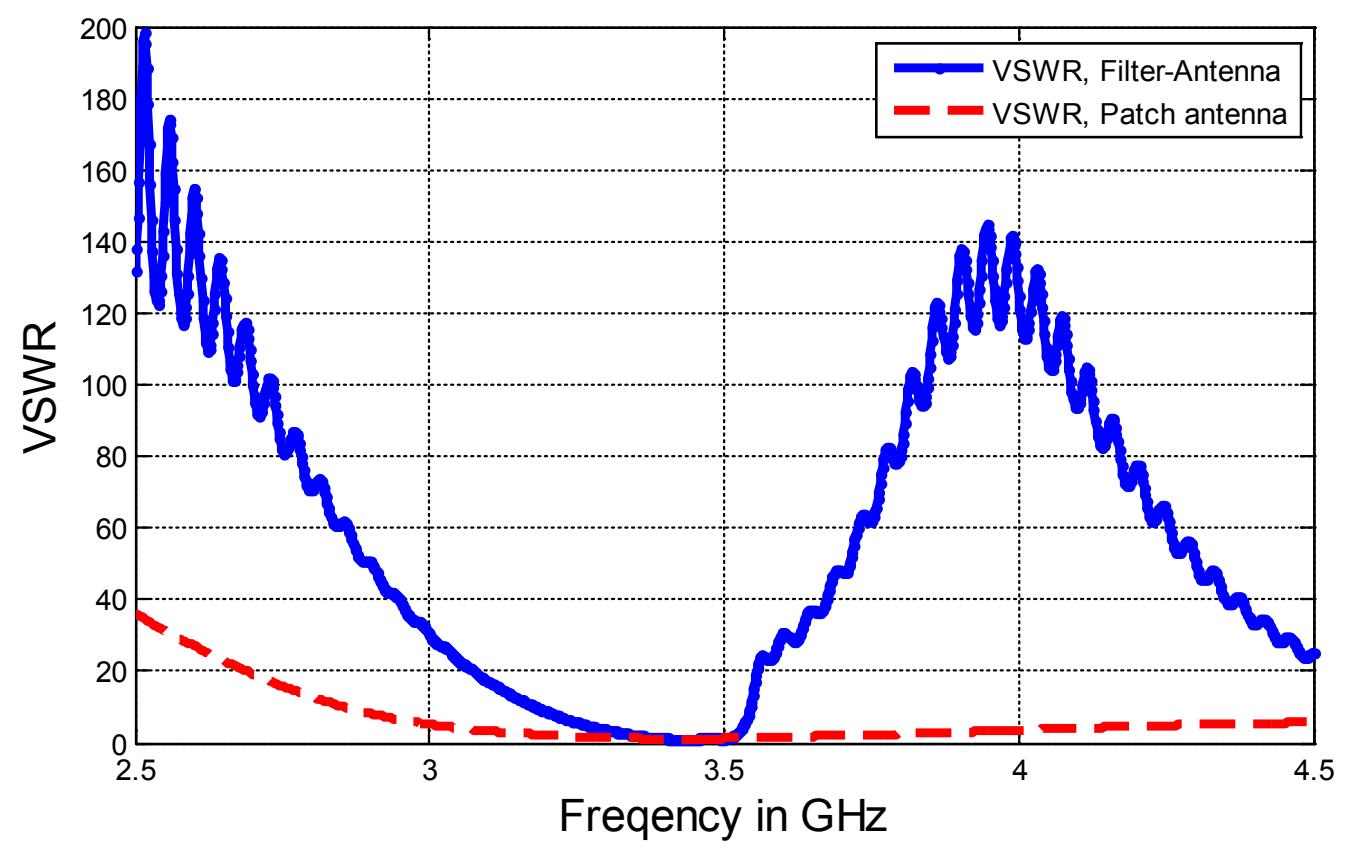

Figure 10: VSWR of the filter-antenna and the patch antenna.

Farfield Gain Abs (Phi=90)

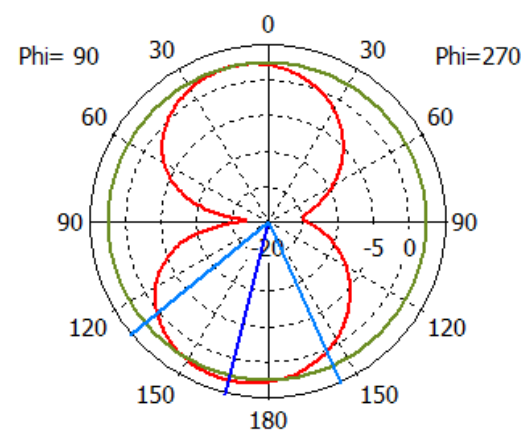

Frequency $=3.42 \mathrm{GHz}$

Main lobe magnitude $=4.9 \mathrm{~dB}$

Main lobe direction $=166.0$

deg.

Angular width $(3 \mathrm{~dB})=74.9$

deg.

Side lobe level $=-0.6 \mathrm{~dB}$

Farfield Directivity Abs (Phi=90)

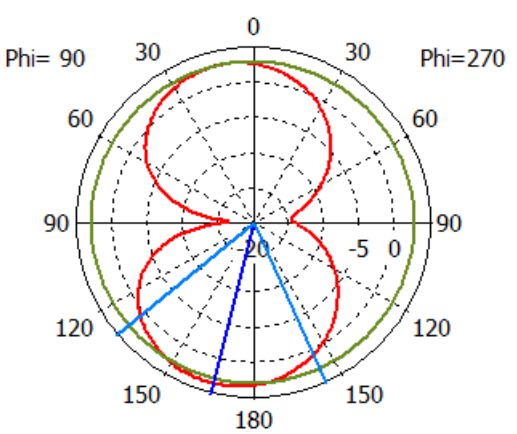

Frequency $=3.42 \mathrm{GHz}$

Main lobe magnitude $=5.4 \mathrm{~dB}$

Main lobe direction $=166.0$

deg.

Angular width $(3 \mathrm{~dB})=74.9$

deg.

Side lobe level $=-0.6 \mathrm{~dB}$

Figure 11: Simulated farfield gain and directivity of the proposed filter-antenna at $3.42 \mathrm{GHz}$. 
Citation: Alkhafaji MK, Sahbudin RKZ, Ismail AB, Hashim SJ (2016) Design of a Selective Filter-Antenna with Low Insertion Loss and High Suppression Stopband for WiMAX Applications. Int J Sens Netw Data Commun 5: 147. doi: 10.4172/2090-4886.1000147

\begin{tabular}{|c|c|c|c|c|c|c|c|c|c|}
\hline Wp & Lp & W5 & W6 & W7 & W8 & L8 & L9 & L10 & L11 \\
\hline 15 & 14.5 & 2 & 6 & 1.9 & 5.9 & 2 & 1 & 0.4 & 2.8 \\
\hline
\end{tabular}

Table 2: Design parameters of the proposed antenna $(\mathrm{mm})$.

\begin{tabular}{|c|c|c|c|c|c|c|}
\hline W9 & W10 & W11 & $\mathbf{W 1 2}$ & $\mathbf{L 1 2}$ & $\mathbf{L 1 3}$ & $\mathbf{L 1 4}$ \\
\hline 6.5 & 1.5 & 0.3 & 0.9 & 3 & 1.8 & 26 \\
\hline
\end{tabular}

Table 3: Filter-antenna bottom view dimensions $(\mathrm{mm})$.

proposed structure provides good skirt selectivity and low loss in the pass band with high reject in the stop band.

\section{References}

1. Chuang CT, Chung SJ (2009) New printed filtering antenna with selectivity enhancement. In Microwave Conference, 2009. EuMC 2009. European pp: 747-750.

2. Yusuf $Y$, Gong $X(2010)$ A new class of 3-D filter/antenna integration with high quality factor and high efficiency. In Microwave Symposium Digest (MTT). IEEE MTT-S International pp: 892-895.

3. Lin CK, Chung SJ (2011) A filtering microstrip antenna array. IEEE Transactions on Microwave Theory and Techniques 59: 2856-2863.

4. Chen X, Zhao F, Yan L, Zhang W (2013) A compact filtering antenna with flat gain response within the passband. IEEE Antennas and Wireless Propagation Letters 12: 857-860.
5. Zuo J, Chen X, Han G, Li L, Zhang W (2009) An integrated approach to RF antenna-filter co-design. IEEE Antennas and Wireless Propagation Letters 8 : 141-144.

6. Kufa M, Raida Z, Mateu J (2014) Equivalent circuits of planar filtering antennas fed by apertures. 2014 20th International Conference on Microwaves, Radar, and Wireless Communication (MIKON) pp: 1-4.

7. Lin CK, Chung SJ (2009) A compact edge-fed filtering microstrip antenna with $0.2 \mathrm{~dB}$ equal-ripple response. Microwave Conference, 2009. EuMC 2009. European pp: 378-380.

8. Sung $Y$ (2010) Microstrip resonator doubling as a filter and as antenna IEEE Antennas and Wireless Propagation Letters 9: 467-470.

9. Tu WH (2010) Sharp-rejection broadband microstrip bandpass filters using loaded open-loop resonator. Microwave Symposium Digest (MTT). IEEE MTT-S International pp: 1-1.

10. Partal HP (2010) Cross coupled wiggly line hairpin filters with high selectivity and spurious suppression. Microwave Conference (EuMC), 2010 European pp: 1265-1268.

11. Lin CK, Chung SJ (2011) A compact filtering microstrip antenna with quasielliptic broadside antenna gain response. IEEE Antennas and Wireless Propagation Letters 10: 381-384.

12. Amaya R, Momciu A, Haroun I (2013) High-performance, compact quasielliptic bandpass filters for $\mathrm{V}$-band high data rate radios. IEEE Transactions on Components, Packaging and Manufacturing Technology 3: 411-416. 